\title{
Assessing the Effectiveness of Child-Centered Play Therapy in Reducing Behavioral Disorders of Primary School Children
}

\author{
Shahabizadeh Zahra \\ M.A. in Clinical Psychology, Department of Psychology, Faculty of Humanities, Neyshabur Branch, \\ Islamic Azad University, Neyshabur, Iran
}

\section{Toozandehjani Hassan*}

Assistant Professor, Ph. D. of Psychology, Department of Psychology, Faculty of Humanities, Neyshabur Branch, Islamic Azad University, Neyshabur, Iran *Corresponding Author Email: H. Toozandehjani@ymail.com

\section{Doi:10.5901/mjss.2016.v7n3s3p104}

\section{Abstract}

The present study aims to investigate the effectiveness of child-centered play therapy in reducing behavioral disorders of primary school children. This research was a quasi-experimental study with pretest-posttest control group design. The sample consists of 30 primary school children suffering from behavioral disorders, who referred to the Center for Counseling and Psychological Services of District 3of Education Department in Mashhad. The participants were assigned to experimental and control groups (15 individuals in each group). Members of the experimental group received 12 sessions of child-centered play therapy while no particular treatment was provided for the control group. Before and after the intervention, Rutter's behavioral disorder scale was applied to the sample. The results of multivariate analysis of covariance indicated that in the post-test, the score of behavioral disorders in children of the experimental group had a significant decrease compared to the control group. The findings of the study revealed that child-centered play therapy reduces primary school children's behavioral disorders.

Keywords: Child-centered play therapy, behavioral disorders, primary school children

\section{Introduction}

Early years in life are considered as one of the most critical stages of growth and development. This period, due to its role and importance in human life, has been always the focus of attention on the part the scientists, psychologists and authors of each era. According to psychologists, this period is a source of psychological trauma in adulthood. All these remarks and attention indicate the significance of this period of life. Therefore, dealing with mental problems and injuries of this period is of great importance (Khoddam, 2009).

One of the issues that involves the childhood of many people and has a long-term impact on their lives are behavioral disorders. Behavioral disorders include various, extreme, chronic and misleading behaviors which range from aggressive actsor sudden arousal to depressive actions. The incidence of these symptoms is unexpected for the observer so that he has a desire to stop these behaviors (SeifNaraqi \& Naderi, 2013). Many researchers regard behavioral disorders as common and debilitating disorders that create a lot of difficulties for the family, environment and child and are accompanied by high levels of social disorders (Shams, Sadr al-Sadat \& Emamipour, 2004).

Behavioral disorders usually first appear in the middle years of primary school period, peaking between 8 and 15 years of age and affect all aspects of children's personal and social life (ShokouhiYekta \& Parand, 2010). In the present era, behavioral disorders in children and adolescents have grown substantially. In the area of education, experts, scholars, teachers, and educators encounter many students with emotional and behavioral problems. Behavioral disorders largely affect children's educational situation and social development to the extent that they cannot properly go through the natural course of growth (Hallahan \& Kafman, 2009).

The pressures arising from the presence of a child with behavioral disorders in the family environment can make an impact on the psychological status of parents and other family members. Denial of reality, rejection of the child's problems, anger and aggression, depression, feeling guilty and sacrificing the lives and aspirations and disruptions in marital relations are among the most important emotional impacts on parents. Also, due to the presence of a child with behavioral disorders, family and social relationships and attending parties, recreations and social activities for families are 
faced with difficulties so that in many instances, this leads to the separation of parents (Keramati, Bolhari \& Asgharnezhad, 2006).

Regarding therapeutic interventions, to improve the psychological status of children with behavioral disorders, extensive efforts have been conducted and recorded in the field of child psychotherapy. One of these interventions that enjoys extensive research and theoretical background is play therapy. Play therapy is a technique that focuses on helping troubled children to solve their problems and at the same time reflects the fact that playing for children is a natural means with the aim that he can reveal and display his internal features though playing, just like those treatments through which adults express their problems by talking (Ray, 2008). Play therapy is a treatment that has been modeled based on healthy interactions between parents and children. Lowen Feld believes that the key role of playing is to lead the child from emotional immaturity to emotional maturity. The purpose of experts who work with children is to accelerate child development, and play therapy is an effective way to improve child development (Bratton et al., 2005).

Play is the most important form of child activity in preschool age that can affect the whole personality of the child and his growth and prosperity in all fields including social, intellectual and moral aspects (Landreth, 2002).

Children who have had sufficient training in play are certainly more able to enjoy better thinking in today's tumultuous world (Baggerly \& Jenkins, 2009). Studies have shown that non-pharmacologic treatments such as psychotherapy using the methods of play therapy have been effective for a significant percentage of children. Whenever verbal language is not enough to express the thoughts and feelings of children, therapists use play therapy to help children express what is troubling them (Paone et al., 2008). The good relationship that forms between the therapist and the child during play therapy sessions provides an important experience that is necessary for treatment. In play therapy, toys are like the child's words and play is the child's language (Landreth, 2002).

Amester (2007; cited in Baggerly \& Jenkins) states that children's play that is their natural means for selfexpression provokes a lot of thoughts, experiences and results and in this respect, play can be applied in the treatment of children. As others have discovered, he has also found that play has a lot of meanings and values to children, including the fact that play is essentially an activity during which children understand, learn and feel comfortable.

Considering the above, this question comes to mind whether play therapy is effective in improving children's behavioral disorders? Thus, the aim of this study is to evaluate the effectiveness of play therapy in improving the behavioral disorders of primary school children.

\section{Methodology}

\subsection{Research design}

This study which is a kind of applied research in terms of goal was conducted as a quasi-experimental study with pretestposttest control group design. In the descriptive analysis of data, statistics of mean and standard deviation were used and in the inferential analysis, multivariate analysis of covariance (MANCOVA) was applied.

\subsection{Population, sample and sampling method}

The statistical population of the present study consists of all primary school children with behavioral disorders who referred to the Center for Counseling and Psychological Services of District 3of Education Department in Mashhad. In this article, the researcher, according to inclusion criteria, selected a sample comprising 30 children from among the children of the statistical population. The selected participants were randomly assigned to two experimental and control groups. Thus, there were 15 children within each group. The reason for choosing this volume for each group was that basically in weekly groups, the presence of twelve members and a leader might be appropriate and in order to remove the effect of the potential loss of members, 3 to 4 individuals can be added to this number (Yalom \& Leszcz, 2005). Also, available random sampling was employed in the way that initially, 30 primary school children with behavioral disorders willing to participate in treatment programs were selected. Then, randomly and based on the list of names, they were assigned to experimental and control groups.

\section{Research Tools}

\subsection{Rutter behavioral disorder questionnaire}

This questionnaire which has been revised by Mehryar is composed of 30 items. Of this number, 24 questions have been 
taken directly from Rutter's questionnaire and 6 questions have been added with regard to Iranian culture. Each of the test materials is scored on a 3-grade scale $(0,1,2)$. This test covers 5 major dimensions including hyperactivity $I$ aggression, anxiety / depression, anti-social behavior / conduct disorder, maladaptive behaviors and attention deficit disorder.

This tool enjoys high reliability and validity. Rutter carried out an experiment on 91 children and used psychiatric questionnaire along with Behavioral Disorder Questionnaire and reported a high percentage of agreement of 0.75 . Yousefi performed the questionnaire along with Bender-Gestalt test on 50 subjects in Shiraz and obtained a high correlation of 0.96 .

\section{Findings}

Among the members of the experimental group, $40 \%$ studied in the first grade of primary school, $26.7 \%$ in the second grade, $20 \%$ in the third grade, $6.7 \%$ in the fourth grade and $6.7 \%$ in the fifth grade. Among the members of the control group, $40 \%$ studied in the first grade of primary school, $20 \%$ in the second grade, $20 \%$ in the third grade and $20 \%$ in the fourth grade. $33.3 \%$ of the fathers of the participants in the experimental group were workers, $46.7 \%$ had self-employed jobs and $20 \%$ were employees. $20 \%$ of the fathers of the subjects in the control group were workers, $33.3 \%$ had selfemployed jobs and $46.7 \%$ were employees. The average age of the subjects in the experimental group was 8.4 years and for the participants in the control group, it was 8.25.

In this section, information on frequency, mean and standard deviation related to the results of conducting Rutter behavioral disorder questionnaire on the subjects in the experimental and control groups in the pre-test and post-test is provided. Table 1 shows descriptive indices of the data obtained from implementing Rutter behavioral disorder questionnaire in the pretest and posttest for each group.

Table 1: Descriptive indices related to the data obtained from implementing Rutter behavioral disorders pretest and posttest

\begin{tabular}{llccccc}
\hline Group & Variable & Number & & Pretest & & Posttest \\
\hline & & & Mean & Standard deviation & Mean & Standard deviation \\
\hline Experimental & Aggression and hyperactivity & 15 & 8.4000 & 1.63881 & 4.8667 & 1.35576 \\
\hline & Anxiety and depression & 15 & 7.7333 & 1.16292 & 6.5333 & 0.91548 \\
\hline & Social incompatibility & 15 & 8.0000 & 1.25357 & 5.4667 & 1.24595 \\
\hline & Anti-Social behavior & 15 & 8.9333 & 1.38701 & 6.4000 & 1.05560 \\
\hline & Attention deficit & 15 & 8.4000 & 1.18322 & 6.0667 & 1.03280 \\
\hline Control score of behavioral disorders & 15 & 41.4667 & 3.33524 & 29.3333 & 2.49762 \\
\hline & Aggression and hyperactivity & 15 & 8.2667 & 1.38701 & 8.4667 & 1.18723 \\
\hline & Anxiety and depression & 15 & 7.3333 & 0.89974 & 7.9333 & 0.96115 \\
\hline & Social incompatibility & 15 & 8.1333 & 1.40746 & 8.1333 & 1.18723 \\
\hline & Anti-social behavior & 15 & 8.2000 & 1.82052 & 8.2667 & 1.48645 \\
\hline & Attention deficit & 15 & 8.3333 & 0.97590 & 8.0000 & 0.65465 \\
\hline
\end{tabular}

As can be seen, the mean of the scores of behavioral disorders in the members of the experimental group which have been completed by the teacher has had a significant decrease in the posttest compared to the pretest. This change is not observed in the control group.

To assess the effectiveness of child-centered play therapy in reducing the behavioral disorders of primary school children, multivariate analysis of covariance was applied. In this analysis, the difference between groups in some variables is measured by controlling one or more other variables that may affect the results. So, to compare the mean scores of behavioral disorders in the subjects of two groups in posttest, multivariate analysis of covariance was used and the effects of pretestas a covariate were controlled.

Before performing multivariate analysis of covariance, its assumptions must be examined. Thus, assumptions of this test were initially studied. To ensure the normal distribution of data obtained from behavioral disorders questionnaire, Kolmogorov-Smirnov test was employed. The results of this test have been presented in Table 2. 
Table 2: Kolmogorov-Smirnov test to ensure the normal distribution of variables scores

\begin{tabular}{lcc}
\hline Variable & Z Smirnov & Significance level \\
\hline Aggression and hyperactivity & 1.035 & 0.151 \\
\hline Anxiety and depression & 0.719 & 0.569 \\
\hline Social incompatibility & 0.845 & 0.603 \\
\hline Anti-social behavior & 0.541 & 0.877 \\
\hline Attention deficit & 1.113 & 0.094 \\
\hline Total score of behavioral disorders & 0.984 & 0.671 \\
\hline
\end{tabular}

As shown in the above table, data obtained from behavioral disorders questionnaire is normally distributed (KolmogorovSmirnov test is not significant in any of the variables). So, the assumption regarding the normality of data distribution has been observed. The assumption of the homogeneity of variances of variables was investigated using Levene test. Results of this test have been provided in Table 3.

Table 3: Levene test to ensure the homogeneity of variances of variables

\begin{tabular}{lcccc}
\hline Variables & $F$ & Degrees of freedom 1 & Degrees of freedom 2 & Sig. level \\
\hline Aggression and hyperactivity & 2.196 & 1 & 28 & 0.150 \\
\hline Anxiety and depression & 0.106 & 1 & 28 & 0.748 \\
\hline Social incompatibility & 1.394 & 1 & 28 & 0.248 \\
\hline Anti-social behavior & 0.648 & 1 & 28 & 0.428 \\
\hline Attention deficit & 1.190 & 1 & 28 & 0.285 \\
\hline Total score of behavioral disorders & 0.040 & 1 & 28 & 0.843 \\
\hline
\end{tabular}

As can be observed, the results indicated that Levene test is not significant in any of the variables. This suggests that the variances of variables are homogeneous. Thus, multivariate analysis of covariance is applicable. The overall results of multivariate analysis of covariance have been provided in Table 4.

Table 4: Overall results of multivariate analysis of covariance

\begin{tabular}{lccccc}
\hline Test type & Value & Hypothetical df & Dffor error & $F$ & $P$ \\
\hline Pillai's Trace & 0.939 & 5 & 19 & 58.917 & 0.000 \\
\hline Wilks's lambda & 0.061 & 5 & 19 & 58.917 & 0.000 \\
\hline Hotelling Trace & 15.504 & 5 & 19 & 58.917 & 0.000 \\
\hline Roy's largest root & 15.504 & 5 & 19 & 58.917 & 0.000 \\
\hline
\end{tabular}

Significance of the indicators of multivariate test, i.e. Wilks's lambda, Hotelling Trace, Roy's largest root and Pillai's Trace $(F=58.917, p<0.0005)$, confirms the fact that a significant difference has been created in at least one of the components of posttest in behavioral disorders questionnaire. Hence, each of these components was studied. Results of this study have been provided in Table 5.

Table 5: Comparing the scores of behavioral disorders posttest in both groups with controlling the effect of pretest

\begin{tabular}{llccccc}
\hline Sources of changes & Variables & F & P-value & Coefficient of effect & Statistical power \\
\hline & Aggression and hyperactivity & 1 & 13.575 & 0.001 & 0.371 & 0.941 \\
\hline & Anxiety and depression & 1 & 3.553 & 0.072 & 0.134 & 0.439 \\
\hline Pretest & Social incompatibility & 1 & 45.094 & 0.000 & 0.662 & 1.000 \\
\hline & Anti-social behavior & 1 & 46.314 & 0.000 & 0.668 & 1.000 \\
\hline & Attention deficit & 1 & 4.255 & 0.051 & 0.156 & 0.507 \\
\hline & & & & & & \\
\hline & Aggression and hyperactivity & 1 & 78.404 & 0.000 & 0.773 & 1.000 \\
\hline Group & Anxiety and depression & 1 & 18.845 & 0.000 & 0.450 & 0.986 \\
\hline & Social incompatibility & 1 & 85.744 & 0.000 & 0.788 & 1.000 \\
\hline & Anti-social behavior & 1 & 63.508 & 0.000 & 0.734 & 1.000 \\
\hline Attention deficit & 1 & 40.086 & 0.000 & 0.635 & 1.000 \\
\hline Error & Total score of behavioral disorders & 1 & 285.627 & 0.000 & 0.925 & 1.000 \\
\hline Total & 23 & & & & \\
\hline
\end{tabular}


As seen in the above table, the results of comparing the posttest in both groups with controlling the effect of pretest indicate that after attending child-centered play therapy sessions, scores of aggression and hyperactivity $\left(F_{(1,23)}=78.404\right.$, $P<0.0005)$, anxiety and depression $\left(F_{(1,23)}=18.845, P<0.0005\right)$, social incompatibility $\left(F_{(1,23)}=85.744, P<0.0005\right)$, anti-social behavior $\left(F_{(1,23)}=63.508, P<0.0005\right)$, attention deficit $\left(F_{(1,23)}=40.086, P<0.0005\right)$ and total score of behavioral disorders $\left(F_{(1,23)}=285.627, P<0.0005\right)$ of the children participating in the experimental group had a significant decrease compared to those in the control group.

\section{Discussion}

The present study intends to investigate the effectiveness of child-centered play therapy in reducing the behavioral disorders of primary school children. The results showed that participating in child-centered play therapy sessions causes to reduce the behavioral disorders of primary school children. This finding is consistent with the results obtained by Greenspan and Wieder (2003), Greenspan and Wieder (2005), Pajareya and Nopmaneejumruslers (2011), Solomon, Necheles, Ferch and Bruckman (2007) and Asadi (2004) who have referred to the positive effects of play therapy on reducing behavioral disorders in children and improving their psychological health and psychosocial development. In explaining the results obtained in this study, the changes that have been produced in children's treatment with communication and social issues as a result of attending child-centered play therapy sessions must be mentioned. Most of the children who participated in this research experienced high levels of stress in the field of social and communication behaviors and this stress also affected their treatment with peers and parents. Children's behavior and communication problems, parental concerns about the slowness of child's social development, low acceptance of society and even other family members towards the child's inappropriate social relationships and low self-efficacy of mothers in dealing with these issues are among the most important factors influencing the increase of their stress (Ashrafi, 2014).

Children's stress in dealing with social and communication problems becomes chronic over time and remains stable. High levels of stress and low self-efficacy make them more inclined to use threatening, aggressive and uncompromising methods and apply inefficient methods of dealing with their parents and peers. Further, high stress and low self-efficacy cause them to less comply with social rules and customs and fail in decision-making about the most appropriate strategies for dealing with others. This has negative effects on children's growth and hinders the development of their social communications.

Considering the fact that children's stress and helplessness in dealing with social problems will have a significant impact on their growth, it seems that in the treatment programs to reduce children's behavioral disorders, these variables must be considered. In child-centered play therapy, attemptshave been made to take this issue into consideration, i.e. the child is placed in an environment where he can externalize his stresses and negative feelings by reflecting them in play. Additionally, in child-centered play therapy, symbolic spaces are created in which children can express those negative emotions that they experience in their relationships with parents and peers but are unable to betray.

Studies have shown that when children's decision-making is considered during the treatment process, positive outcomes of treatment are doubled (McConachy et al., 2007); the point that is emphasized in child-centered play therapy. Giving children freedom in the process of treatments that are considered for them has beneficial effects for their psychological condition. Various studies have shown that children's involvement in the process of treatment orientation has a considerable impact on improving their mental health (Kane et al., 2010). On the other hand, this improvement of children's health and psychological status certainly influences their parents' treatment with them and consequently, brings positive outcomes for children. In the present study, this issue is presented in this way: Children attending child-centered play therapy sessions showed a decrease in their behavioral disorders and helplessness in the face of social problems and opportunities (such as not greeting the guests and hosts, talking loudly in front of others, getting in a huff, aggression, etc.). This makes mothers feel that their child enjoys a better psychological situation and thus, they are able tobetter control traumatic emotional reactions in relation to their child. Consequently, this phenomenon had a favorable impact on children's psychological status and promoted the growth of their behavioral skills and reduced their behavioral disorders.

In this research, in addition to improving the child's psychological status and his manner of treatment with different problems, strengthening socially desirable behaviors of the child was also emphasized and the children indirectly were taught social skills. Since this training took place in the context of thesymbolic relationship between children and the people around (play therapy in which others participate symbolically using toys), it was transferred to the home environment and family and it can be said that treatment continued at home. To ensure this issue, the researcher of the present study examined parent-child interactions in the home environment and the results indicated that the manner of parent-child interactions in the home environment has no significant difference with symbol-makings of the treatment environment. This issue has been in the same way in previous studies. Child-centered play therapy is one of the 
interventions aimed at improving the child's interaction with the environment and previous researches on evaluating the impact of this program indicate increased mental health and psychosocial adjustment and development of children (Baggerly \& Jenkins, 2009).

Another mechanism of effect in child-centered play therapy that affects the decrease of children's behavioral disorders is the change in the attitude of the child and his parents towards his behavioral problems. Mothers' interaction with the therapists that takes place along with attending play therapy sessions cause the mothers to gain a proper understanding of their child's status on growth continuum, development of his social skills and educational and therapeutic interventions, learn how to control their child's challenging behaviors, have a more positive attitude about their child's progress and finally, exert less pressure on their child to learn how to properly behave in society. Certainly, when the child is freely encouraged to learn the behaviors whose positive results have been shown to him, he will have better performance compared to the time when parents only by force and threat want him to do such work in a certain situation. Therefore, as expected, behavioral disorders in children declined after participating in child-centered play therapy sessions. Since child-centered play therapy is taken from emotion-focused approaches, it focuses more on emotions in dealing with behavioral disorders of children. In fact, according to this view, children's emotional development determines what method the child adopts in dealing with communication situations. Also, manner of controlling behaviors and setting extreme ideals depend on his emotions. This provides a wide range of facilities for treatment so that the therapist should focus on changing emotions and creating alternative modes of experiencing, coping and controlling the internal events such as emotions associated with social behaviors towards close individuals.

In this regard, one of the issues that is taken into account in child-centered play therapy is emotional expression in the right and constructive manner. The task of the play therapist in play therapy sessions is to create a supportive and friendly atmosphere where the child can express the unpleasant emotions related to his relationship with parents and significant others without experiencing feelings of guilt. The same thing happened in play therapy sessions of the present study and its main underlying factor was the supportive and friendly atmosphere of the sessions. According to the founders of child-centered play therapy approach, emotional expression in a supportive atmosphere that is not followed by feeling of guilt is the main factor in improving the close contacts of children. Child-centered play therapy puts a heavy emphasis on emotional expression. Emotional expression in an appropriate manner makes the child closer to his parents and this closeness which is accompanied by improvement of the relationship fosters the child's social skills. So, it is expected that the child's behavioral disorders be significantly reduced after attending child-centered play therapy sessions.

According to the findings of this research, the principles of child-centered play therapy such as the child's participation in the treatment process and encouraging the symbolic expression of emotions provide the ground for reducing behavioral disorders in children. Results of this study show that the child's participation in his own treatment process and creating a child-centered supportive environment, in which he can expresspleasant and unpleasant emotions freely and without feeling of guilt, have a positive impact on reducing his behavioral disorders and improve his relationship with the environment. Moreover, maternal knowledge of what happens in play therapy sessions and increasing mothers' awareness regarding the root of their children's problems cause them to better accept the child's behavior, take a more positive attitude about the progress of their child's social skills and ultimately, reduce many of their own stresses and concerns associated with the social development of children. All of these instances reduce the child's behavioral disorders and facilitate the development of his social skills.

As can be seen, the research hypotheses were confirmed and the results showed that child-centered play therapy helps to reduce the behavioral disorders of primary school children. The results of this study and previous researches support play therapy techniques and interventions based on the child-centered approach to reduce the behavioral disorders and improvethe psychological status of primary school children.

\section{References}

Asadi, K. (2004). Acute lymphoblastic leukemia in children. Darman Publications.

Baggerly, J., \& Jenkins, W. (2009).The effectiveness of child-centered play therapy on developmental and diagnostic factors in children who are homeless. International Journal of Play Therapy, 18, 45-55..

Bratton, S. C., Ray, D. C., Rhine, T., \& Jones, L. (2005). The efficacy of play therapy with children: A meta-analytic review of treatment outcomes. Professional Psychology: Research and Practice, 36, 376-390.

Greenspan, S. and Wieder, S. (2005). Engaging Autism. Da Capo Press.

Greenspan, S. I., \& Wieder, S. (2003). Developmental patterns and outcomes on Infants and children with disorders of relating and communicating: A chart Review of 200 cases of children with Autistic Spectrum Diagnoses. Journal of Developmental and Learning Disorders, 1, 87-141. 
Halahan, D. \& Kaufman, J. (2008).Psychology of Exceptional Children. Translated by F. Maher. Tehran: Roshd.

Keramati, K.,Bolhari, J. \&Asgharnezhad, A. (2006). Effect of father loss on behavior disorders inprimary school children. Journal of Psychiatry and Clinical Psychology (thought and behavior), 4 (12): 312-395.

Khoddam, H. (2009). Behavioral disorders and the related factors in school age children in Gorgan. Journal of Nursing Research, 4:2937.

Landreth, G. L. (2002). Play therapy: The art of the relationship (2nd ed.). New York: Brunner-Routledge.

Pajareya, K., \& Nopmaneejumruslers, K. (2011). A pilot randomized controlled trial of DIR/Floortime ${ }^{\mathrm{TM}}$ parent training intervention for pre-school children with autistic spectrum disorders. Autism, 15(5), 563-577.

Paone, T., Packman, J., Maddux, C., \& Rothman, T. (2008). A school-based group activity therapy intervention with at-risk high school students as it relates to their moral reasoning. International Journal of Play Therapy, 17, 122-137.

Ray, D. C. (2008).Impact of play therapy on parent-child relationship stress at a mental health training setting. British Journal of Guidance \& Counselling, 36, 165-187.

SeifNaraqi, M. \& Naderi, A. (2013).Psychology and Education of Exceptional Children. Tehran: Arasbaran Publications.

Shams, H., Sadro Sadat, S. J., Emami Poor, S. (2004). Behavioral disorders in children of addicted fathers. Journal of Rehabilitation, 17, $32-38$.

ShokouhiYekta, M \& Parand, A. (2010).Behavioral disorders of children and adolescents. Tehran: Teimourzadeh Publications.

Solomon, R., Necheles, J., Ferch, C., \& Bruckman, D. (2007). Pilot study of a parent training program for young children with autism: The PLAY project home consultation program. The National Autistic Society, 11(3), 205-224.

Yalom, D. I. \& Leszcz, M. (2005). The Theory and Practice of Group Psychotherapy. New York, Basic Books. 